\title{
LEVANTES: PARA UMA ABORDAGEM ESTÉTICA DA POLÍTICA
}

\section{UPRISINGS: TOW ARDS NA AESTHETIC APPROACH TO POLITICS}

\author{
Alexandre F. Mendes ${ }^{1}$
}

Resumo: O ano de 2018 está marcado por uma coincidência cronológica que trouxe o tema dos levantes para o centro da discussão política e acadêmica. É nele que a memória dos 50 anos do grande ciclo de Maio de 1968, já inscrita em uma certa longa duração, encontra a lembrança viva e recente dos 05 anos de Junho de 2013, cujas repercussões são ainda incertas e enigmáticas. Neste artigo, sustento que as várias dimensões e os vários "mundos" contidos nos levantes reclamam uma relação entre estética e política que não pode ser limitada a mais uma visão sobre o ciclo de revoltas. Pelo contrário, trata-se de compreender como os próprios pontos de vistas lançados por dentro do acontecimento arrastam a nossa percepção e reclamam, não apenas novas formas de pensar, mas, principalmente, novos modos de existir.

Palavras-chave: levantes, imagem, estética, política.

Abstract: The year of 2018 is marked by a chronological coincidence that brings out the issue of uprisings to the very center of political and academic discussion. It is on this terrain that the memory of the 50 years of May 1968, which could be already inscribed in a longue durée, finds the vivid and recent memory recalled in the five years of June 2013, whose repercussions are still uncertain and enigmatic. In this article, I argue that the various dimensions and the many "worlds" contained in the uprisings call for a relationship between aesthetics and politics that cannot be limited to one more vision of the cycle of revolts. On the contrary, the question is to understand how the points of view launched within the event could drag our perception and demand, not only new forms of thinking but, mainly, new modes of existing.

Keywords: uprisings, image, aesthetics, politics.

\section{INTRODUÇÃO}

O ano de 2018 está marcado por uma coincidência cronológica que trouxe o tema dos levantes para o centro da discussão política e acadêmica. É nele que a memória dos 50 anos do grande ciclo de Maio de 1968, já inscrita em uma certa longa duração, encontra a lembrança viva e recente dos 05 anos de Junho de 2013, cujas repercussões são ainda incertas e enigmáticas. Neste artigo, sustento que as várias dimensões e os vários "mundos" contidos

\footnotetext{
${ }^{1}$ Professor Adjunto da Faculdade de Direito da UERJ.
} 
nos levantes reclamam uma relação entre estética e política que não pode ser limitada a mais uma visão sobre o ciclo de revoltas. Trata-se de compreender como os próprios pontos de vistas lançados por dentro do acontecimento ${ }^{2}$ arrastam a nossa percepção e reclamam, não apenas novas formas de pensar, mas, principalmente, novos modos de existir.

Por isso, sustentamos que o movimento anômalo produzido pelos levantes não pode ser simplesmente sobreposto diretamente por uma linha discursiva já formada (uma teoria política, por exemplo), ou uma prática política que nos convoca a tomar partido (uma frente partidária, neste segundo exemplo). Ele engendra uma abertura por fora de toda figuração ou representação que altera radicalmente os nossos modos de ver, de falar e de sentir, ou seja, provoca uma alteração de todos os parâmetros que implica em uma nova distribuição do sensível. A reviravolta estética é imediatamente política porque é capaz de fazer-ver novas realidades que, mesmo existindo antes da inflexão, ainda não haviam sido instauradas com força suficiente para gerar uma transformação daquele atual "estado de coisas".

Pretendemos levantar essas questões através de uma análise de autores que problematizam a relação entre estética e política no campo da filosofia da arte (DidiHuberman), da crítica literária (Blanchot) e da filosofia (Étienne Souriau, Deleuze, Guattari e Rancière). Para isso, tomaremos como ponto de partida o catálogo elaborado por DidiHuberman em 2017, cujo título é Levantes, e, para o desenvolvimento do argumento, inserções nas obras de Kafka, aqui lido por Blanchot, e do diretor de cinema Alain Resnais, comentado por Deleuze. O percurso termina com a diferenciação entre uma visão mais tradicional dos levantes, inserida no grande quadro da filosofia política (Antonio Negri e Judith Butler), e uma abordagem ligada à "estética do Ser", extraída da obra de Étienne Souriau, por David Lapoujade.

Esse caminho nos permitirá refletir, em termos mais gerais, sobre todo um léxico que emerge da relação entre política e estética: descentramento, ambiguidade, tomada de posição, fascinação, percepção, gesto e modos de existência, e suas implicações para uma análise dos levantes que não busca se colocar no exterior do acontecimento. Em termos específicos, conferizndo um ritmo à própria reflexão geral, será possível problematizar a relação entre imagens e o material vivo dos levantes, buscando não cair na visão redutora e mistificadora de uma simples estetização da política.

\footnotetext{
2 Para o conceito de acontecimento, conferir: DELEUZE, G; GUATTARI. "Mai 68 n'a pas eu lieu". In: LAPOUJADE, D. (Org.). Deux régimes de fous et autres textes. Paris: Les Éditions de Minuit, 2003.
} 


\section{LEVANTES: A PAIXÃO DA IMAGEM}

Para iniciar o nosso roteiro, proponho a leitura de uma imagem, El Quijote de la Farola (foto de Alberto Korda), que faz parte da exposição Soulèvements (Levantes), organizada pelo filósofo da arte Didi-Huberman que, depois de passar por Barcelona, Montreal e Cidade do México, chegou em São Paulo no dia 17 de outubro de 2017 e terminou o seu percurso mundial em Buenos Aires (no dia 29 de janeiro). Integra a exposição um catálogo, contendo não só as imagens, mas uma série de ensaios escritos por conhecidos filósofos contemporâneos, como Judith Butler, Jacques Rancière, Antonio Negri, o próprio DidiHuberman, entre outros (DIDI-HUBERMANa, 2017).

A escolha da imagem permite trazer algumas questões para a discussão que proponho. Primeiro, do ponto de vista geral, trata-se de pensar o contexto que envolve a iniciativa, realizada logo após os últimos suspiros do ciclo da Primavera Árabe e cerca de 50 anos depois das irrupções de 1968. O conjunto de imagens, e de reflexões suscitadas por elas, compõe um mosaico que invariavelmente põe sob questão o day after dos levantes, seus efeitos, suas permanências e sua possível atualidade. Segundo, a partir de uma questão suscitada pelo próprio curador e por Jacques Rancière, trata-se de indagar se a exposição não reduziria potentes e dramáticos atos de revolta a um "objeto" a ser contemplado nos depurados corredores dos museus. Que relação que as imagens poderiam tecer, mesmo confinadas em um Museu, com o material intensivo dos levantes?

As duas questões globais nos levam para a escolha da imagem que separamos para iniciar a discussão (voltaremos aos pontos gerais no final da intervenção). Vemos, então, a estranha posição ocupada por um manifestante durante demonstrações massivas e populares de apoio à Revolução Cubana (1959), ocorridas logo após a queda do regime do ditador Fulgêncio Batista. O homem fotografado, como todos os outros apoiadores, veste uma espécie de uniforme no qual se sobressai um grande chapéu com a bandeira de Cuba, símbolo que também aparece costurado em sua camisa. No entanto, ao contrário de todos os outros, ele se descola da multidão e se acomoda no alto de um poste de luz, apresentando um olhar inclinado e um gestual que indica reflexão. O que o manifestante estaria pensando? Por que não está seguindo a multidão? Ele se deslocou para contemplar o apoio massivo à revolução 


\section{RFD}

ou para lançar sobre ela um conjunto de interrogações? Ele é contra ou a favor de Fidel Castro? Se o caso é de desconfiança, por que ele se veste como todos os outros?

Para Didi-Huberman, que comenta esta específica fotografia em uma entrevista sobre o catálogo, a foto tirada por Korda cria um espaço de ambivalência que é próprio da posição tomada pelas imagens, ao contrário do ato de tomar partido, que pressupõe clivagens claras e um espaço já recortado. Para ele, é esta irredutível ambiguidade que gera, desde Platão, tanto nos filósofos como nos "militantes" da política em geral, uma permanente desconfiança com relação à posição tomada pelas imagens. O problema é trabalhado no livro Quando as imagens tomam posição (2009/2017), a partir da tensão entre estética e política na obra de Brecht, sendo a distinção entre partido e posição descrita da seguinte forma: "Ali onde o partido impõe a condição preliminar de uma partida em detrimento das outras, a posição

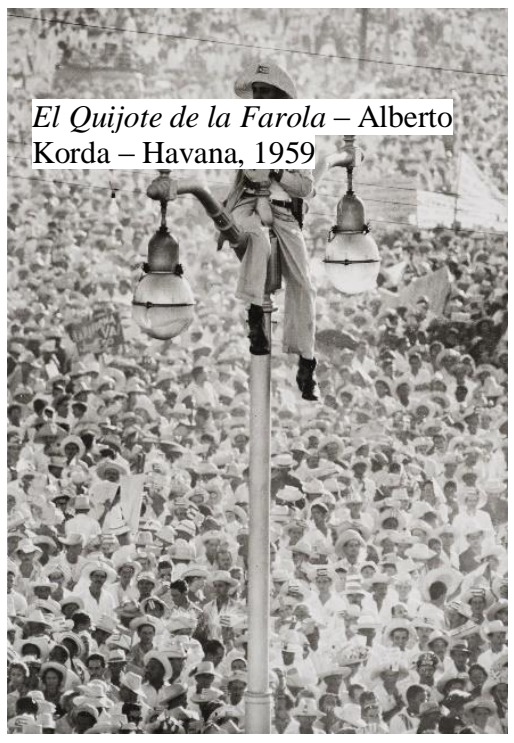
supõe uma copresença eficaz e conflituosa, uma dialética das multiplicidades" (HUBERMAN, 2017b, p. 113).

Assim, enquanto uma tomada de partido estabelece uma geometria baseada em linhas retas e círculos fechados, um “avante!" que, ao mesmo tempo, se dá no ritmo da coesão de grupos de ação (o partido revolucionário, por exemplo), uma tomada de posição opera por desvios permanentes, e por círculos abertos e descentrados que se movem por fora de traçados já dados. É Maurice Blanchot, lembrado tantas vezes por Huberman, que articula, justamente, os três termos: a errância do desvio, os círculos descentrados e o espaço ambíguo ou, em outros termos, o espaço do deserto ou da criação literária.

No conhecido texto Falar não é ver, publicado no livro A conversa infinita (1969/1993), Blanchot compõe um diálogo para explicitar que a palavra encontrar não significa obter ou alcançar um resultado prático ou científico. Encontrar (trouver), ao contrário, estaria próximo do movimento de girar, rodear (tourner), dar a volta, andar ao redor. Encontrar um canto, por exemplo, seria bordejar um movimento melódico, fazê-lo rodar. A busca pressupõe constantes desvios, dobras, uma rotação sem retidão que assume como percurso as próprias linhas de inflexão (BLANCHOT, 1993, p.).

Ela também pressupõe girar em torno de um centro, mas com a peculiaridade de que o centro nunca está ali, esse estranho movimento que opera por uma rotação liberta do jugo 


\section{RFD}

da centralidade. O diálogo avança a partir da conclusão que buscar é de fato errar: "dar voltas e mais voltas, abandonar-se à magia do desvio" (BLANCHOT, M. 1993, p.). É caminhar em regiões fronteiriças e na fronteira do próprio caminhar. Errar é fazer o movimento de retorno, mas deparar-se com o velho ponto de partida, agora turvo ou apagado: "é essa força árida que desloca a paisagem, devasta o deserto, abisma o lugar" (idem).

A figura do deserto, por sua vez, aparece também em outro texto de Blanchot, que integra o livro O espaço literário (1955/2011), mais precisamente sobre a relação de Kafka com o seu êxodo para o outro deste mundo: "será que eu habito agora no outro mundo? Ousarei dizê-lo?". O deserto aqui aparece como um espaço de migração, um local ainda menos seguro que o próprio mundo, um outro do próprio mundo, uma região que é a do erro sem fim, na qual subsiste uma tensão que sempre ameaça o caminho, que pode fechar o espaço do erro, transformando-o em limite: de um caminho sem objetivo à certeza de um objetivo sem caminho.

Blanchot busca no Diário de Kafka, nas anotações realizadas em 1922, a percepção de que as forças áridas impunham aos homens duas opções: "ou buscar a Terra Prometida do lado de Canãa ou buscá-la do lado deste mundo que é o deserto". Da primeira opção, a obediência ao comando de Deus, o deserto como simples passagem e a promessa de fartura e conforto no fim do caminho. Da segunda, a ausência de qualquer centro ordenador, o deserto como morada nômade e o mundo como um imenso lado de fora - uma viração do próprio mundo (BLANCHOT, M, 2011, p. 85).

O deserto contém, ainda, outra força que é a de provocar uma desorientação na distância que existe entre a visão e o objeto visto. O intervalo mensurável que garante a visão de um conjunto se perde e é arrastado por aquilo que Blanchot denomina de fascinação (idem, p. 24). Aqui, o olhar não mantém uma distância necessária e retilínea dotada de uma medida com relação ao objeto, mas é capturado, arrancado, torcido e absorvido por aquilo que é visto. A percepção é desgarrada do seu pacto seguro e produz uma nova visão: "que não é mais possibilidade de ver, mas impossibilidade de não ver, a impossibilidade que se faz ver" (idem).

Se o objeto à distância é a imagem, a fascinação é a paixão da imagem. Blanchot denomina esse duplo de "duas versões do imaginário", que repousa, justamente, em uma permanente ambiguidade (idem, p. 289). Esta deixa de ser apenas a confusão causada pelo duplo sentido (que em alguma hora se resolverá no entendimento), para configurar uma 


\section{RFD}

tensão de passagem entre aquilo que é feito como imagem do mundo (nosso olhar voltado para os objetos) e aquilo que é desfeito pela imagem, carregando-nos para o meio indeterminado da fascinação (uma visão sem medida). A ambiguidade se torna, portanto, a condição do próprio fascínio.

Então, se a escrita pode estabelecer uma relação privilegiada com o espaço literário, é porque ela opera em dois níveis. Primeiro, cortando o uso empírico das palavras no cotidiano afastando-as do campo de visibilidade já posto, ou seja, retirando-as da subordinação existente entre o dizer e o ver (que sentido faria escrever sobre o que já se vê?). Segundo, articulando-se com um murmúrio infinito que emerge das ruínas das palavras e, através dele, ser arrastado pelo poder do indeterminado. E é aí que nos deparamos novamente com a ambiguidade que atravessa a fascinação: o escritor acredita ter posse de toda a fala, de uma espécie de "fala original", mas só o faz tornando-se muito fraco: ele mesmo perde o seu "Eu", e se põe diante de processos que são cada vez mais impessoais.

É assim que Blanchot descreve o paradoxo de Kafka. A caminhada para o deserto significa estabelecer uma relação com forças cada vez mais intensas, mediante um enfraquecimento do sujeito e do cotidiano que o cerca. É o exemplo de escrita contido também no livro $O$ processo, lido aqui por Deleuze e Guattari (DELEUZE; GUATTARI, 1975/2002): o apagamento da figura empírica da Justiça (suas instituições, códigos e procedimentos) torna possível uma visão do processo como relação de força, como fluxos de matéria intensiva e de tensores que circulam sem considerar as fronteiras visíveis do mundo organizado no cotidiano (o processo atravessa a família, os vizinhos, o trabalho, a casa etc.). E é Titorelli, aquele que "faz ver" a Justiça em seus quadros repetidos, que evidencia as duas funções abstratas do processo: viver diante de uma absolvição aparente (a quitação é sempre aparente e antecede uma nova dívida) e uma moratória ilimitada (a dívida se torna eterna).

É no espaço ambíguo entre a imagem do mundo e o que desfaz essa própria imagem, que Kafka dá visão (fabrica uma percepção, uma visibilidade superior) às "forças diabólicas" que assombrariam todo o século XX (a burocracia soviética, o americanismo e fascismo) e, por isso, expõe uma engrenagem que será objeto de contínuas resistências (idem). Daí uma segunda ambiguidade: a recusa de Kafka a aderir às narrativas políticas do início do começo do século XX (socialismo, anarquismo, social-democracia, fascismo, os nacionalismos etc.), ou seja, à convocação para integrar um "Povo", abre espaço a uma relação intempestiva com todas as singularidades que irão resistir aos dispositivos de poder da burocracia, do 
endividamento e do controle: a paixão da imagem é a própria invenção de um outro povo (minoritário), que não cabe nos recortes de visibilidade e nos dicionários organizados pelos poder.

Portanto, se errância, descentramento, ambiguidade e deserto indicam uma recusa a escolher um ponto de partida em detrimento de outros ("tomar partido"), não é para sucumbir a qualquer niilismo ou passividade, mas, pelo contrário, para ascender a uma posição que faz ver e ouvir as resistências anônimas e impessoais que não encontram visibilidade ou enunciação nas representações empíricas do mundo cotidiano. A linearidade da partida, que pressupõe sair de um ponto para chegar a outro, é substituída por posições que são definidas a cada lance e que formam uma curvatura capaz de seguir permanentemente a emergência das singularidades ou, com Didi-Huberman, a coexistência de multiplicidades (no caso de Kafka, o procedimento envolve uma circularidade entre as cartas, as novelas e os romances, que se alternam a cada vez que surge um bloqueio criativo).

\section{FENDER A IMAGEM: O LUGAR NÃO COMUM ONDE OS PONTOS DE VISTA SE ENCONTRAM}

Podemos enfrentar agora as duas questões gerais definidas no início da intervenção, isto é, o exame da atualidade dos levantes e sua relação com o tipo de visibilidade produzida por imagens expostas nos museus. Saltaremos da foto de Alberto Korda, sobre o Quixote cubano, para o filme Hiroshima mon amour, dirigido por Alain Resnais, com roteiro de Marguerite Duras, e que estrou no mesmo ano de 1959. Por que mencionar este filme? Como extrair a partir dele uma interrogação sobre a posição das imagens e a relação entre fascínio e visibilidade?

O filme inicia, justamente, com um passeio, em estilo documentário, no museu que abriga as representações visíveis do horror de Hiroshima: fotos das vítimas, mostras de cabelo, ferros retorcidos, ruínas, pedras e reconstituições das cenas de morte e sofrimento. A sequência de imagens é reforçada por uma voz em off, a da própria protagonista, que afirma ter visto tudo em Hiroshima, ter acompanhado o terrível fato pelos jornais, "desde o primeiro dia". A outra voz em off, do outro protagonista, rebate a afirmação dizendo, repetidas vezes: “você não viu nada em Hiroshima, nada”. 
Com o fim da sequência documental, é iniciada a outra parte do roteiro que mostra a relação entre uma atriz francesa, nascida na pequena cidade de Nevers, e um arquiteto japonês, nascido em Hiroshima. Uma segunda camada de imagens e representações do bombardeio surge em razão das gravações do próprio filme que motivou a viagem da protagonista, uma produção internacional cujo objetivo é defender "a paz mundial". Mas agora essas imagens são cruzadas pelo forte caso de amor vivenciado pelo casal, em uma paixão que se intensifica e percorre cada instante da relação entre os dois.

A irrupção dessa paixão e a iminente separação do casal, ambos casados e afastados pela distância entre França e Japão, estabelece um estado de tensão que culmina na revelação, pela protagonista, do seu primeiro caso de amor em Nevers, um soldado alemão morto no momento da liberação. O trauma da morte do amante (que durou dois dias e foi acompanhada até o fim) e a forte reação da cidade contra o relacionamento, considerado uma colaboração com o inimigo, resultaram na decisão familiar de trancá-la em uma cela fria e úmida. Considera louca por muito tempo, com o final da guerra, sua mãe incentiva uma fuga para Paris, justamente no dia que precede o lançamento da bomba atômica.

A cena da revelação é o ponto alto do filme. Durante uma conversa no bar, momentos antes da forçada separação, a protagonista acessa as camadas já disformes do passado e as atualiza no presente, chegando a confundir o amante japonês (ex-soldado na mesma guerra) com o jovem alemão. Aceitando a passagem para o impessoal, o próprio protagonista estimula o embaralhamento e vibra por ser o único a ter conhecido a estória, após quatorze anos de silêncio. A intensidade da experiência cria um âmbito de "coexistência de multiplicidades", com a intromissão recíproca entre passado e presente, Hiroshima e Nevers, aliados e inimigos, memória singular e memória mundial, substituindo o ponto de partida da História (uma memória aprisionada) por diferentes posições ou perspectivas que se alternam em variação contínua.

O casal é assim arrancado da experiência do cotidiano (Hiroshima e Nevers retomando a rotina no pós-guerra), e é lançado em um plano indeterminado onde o próprio espaçotempo perde a linearidade e desencadeia um movimento errante, compondo os círculos descentrados de Blanchot. Hiroshima está em Nevers (a liberação, a morte do soldado, a prisão, a loucura, o fim da guerra, a fuga para Paris) e Nevers está em Hiroshima (a derrota japonesa, o horror imposto pelos vitoriosos, a "vitória envenenada" nos termos de Brecht, a reintrodução do Japão no circuito americano e europeu). O passado posto em relação 


\section{RFD}

modifica a teia do próprio presente, Hiroshima se torna a possibilidade de reconciliação da protagonista com Nevers (a cura das feridas, a exigência de continuar vivendo, "uma cidade talhada pelo amor"), e Nevers, para o protagonista, se torna o presente de Hiroshima, a imagem da jovem amante quando era livre de suas atuais constrições (a marca da guerra, o casamento, os filhos, a vida adulta), ou a possibilidade de viver um novo amor, extraindo das ruínas da cidade japonesa um novo feixe de horizontes possíveis e novas potencialidades (uma renovada vida pós-horror).

Assim, a frase que dá início ao filme, "você não viu nada sobre Hiroshima", ganha uma nova expressão. Deixa de indicar a impossibilidade de experimentar a tragédia em razão de distâncias culturais, nacionais e pessoais - a falta de uma espécie de "experiência verdadeira" - e passa a expressar o próprio limite da visibilidade como mirada para um objeto. Antes da passagem para a fascinação (o plano informe constituído pelo segundo imaginário), era impossível ver Hiroshima, porque a sequência das imagens documentais, paradoxalmente, provocava o afastamento das intensidades que produzem o fascínio, retendo-as como simples ausência (estamos ainda em Blanchot).

Para Deleuze, em comentário sobre o filme (DELEUZE, 1985/2013), essa memória é tecida, não por uma identidade coletiva que pode ser produzida em um povo, um país, um grupo, uma família, ou um personagem, mas por "lugares não comuns" que expressam uma multiplicidade de pontos de vista sobre o que aconteceu (DELEUZE, 2013, p. 114). Assim, Resnais inicia com uma memória e uma perspectiva construídas coletivamente (os acervos nacionais, a Biblioteca, o Museu, o filme-documentário de cunho pacifista) para acabar atingindo "o paradoxo de uma memória a dois, de uma memória de várias pessoas (...), que compõe uma memória mundial" (idem). Assim como no espaço literário, o lugar não comum é o espaço de encontro e conexão entre diferentes perspectivas, distintos pontos de vista, alguns ainda em potencial, que permitem, paradoxalmente, a constituição de uma memória comum.

Foi preciso fender a superfície das imagens, quebrar o tipo de visibilidade organizado pelos museus (uma memória coletiva que se refere a países, geografias, tempos e pessoas determinadas), para fabricar outra visão, que percorre agora um plano de intensidades e de potencialidades. A própria técnica utilizada por Resnais permite que o salto seja dado: a sequência de fotos do horror é substituída, na última parte do filme, por travellings que percorrem a arquitetura das cidades (Hiroshima e Nevers) dotando-as de uma expressividade 
própria. Por sua vez, a linguagem se descola das imagens, se emancipando do papel subordinado de descrição e buscando o seu próprio limite: as relações entre a cidade, o amor, o corpo, a vida, as mutações imperceptíveis e definitivas produzidas pelo encontro e, por fim, uma pura relação subtraída da própria linguagem.

\section{UMA ESTÉTICA DA POLÍTICA E DOS MODOS DE EXISTÊNCIA}

Podemos, então, retornar à questão geral sobre a relação entre a sequência de imagens que anima a exposição e uma indagação sobre a atualidade dos levantes no atual contexto global. Como passar da constituição de uma memória coletiva dos levantes através de imagens que percorrem séculos - transformando-o em um mesmo objeto a ser olhado - para a constituição de múltiplas posições, ou pontos de vista, que podem ser suscitados pela paixão da imagem? Elas poderão arrastar os nossos olhares na direção de novos planos, modos de existência e conexão entre diferentes perspectivas, como no filme de Resnais e Duras? Elas poderão servir de intensificadores para novas formas de percepção que possam seguir os rastros, os traços e as potencialidades deixadas pelos levantes que sacudiram o mundo? Elas servirão como um ponto de partida que elimina esboços de novas possibilidades ou marcarão uma tomada de posição que garante a tensão e a ambiguidade de uma coexistência de multiplicidades?

Utilizando essa problematização como um critério distintivo das contribuições deixadas pelos filósofos que participam do catálogo, mesmo que por aproximação, podemos identificar duas tendências gerais que apontam para o modo como a filosofia política e a filosofia da arte têm abordado a atualidade dos levantes. A primeira busca inscrevê-los em longos fios históricos constituídos através dos últimos séculos, em densas camadas de memória coletiva, em um desfile de imagens que remete aos grandes processos insurrecionais, em uma lógica de fins e valores definidos de um ponto de vista externo às próprias dinâmicas, servindo para determinar o que seria um levante democrático ou autoritário, ou o que seria uma ontologia negativa ou positiva. Os levantes aparecem como um mundo externo a ser analisado e avaliado e, portanto, a reflexão quase sempre toma a forma de um juízo.

Parece ser o caso de Antonio Negri, que reconhece uma multiplicidade de situações de levante (conduzidos por imigrantes, endividados, jovens de periferia etc.) para inscrevê- 


\section{RFD}

los nos anos epônimos de 1848, 1871, 1917, chegando aos ciclos altermundialistas e à Primavera Árabe. Eles representariam o paradigma de um "movimento que cresce, continua, se aprofunda, mesmo que por meio de derrotas" (NEGRI, A. 2017. p. 43). Uma espécie de "sedimento secular que leva pessoas a sacudir os limites do poder com cada vez mais força" (idem). Uma "linha vermelha" que ligaria as tentativas de ruptura da ordem vigente a um "projeto de mundo futuro" (idem, p. 42). O campo da indignação, aqui, é reduzido a uma ontologia negativa que precisaria realizar uma passagem para a positividade de uma ontologia constituinte que "sopra da Comuna aos sovietes, das insurreições metropolitanas às primaveras do novo proletariado" (idem, p. 44).

Da mesma forma, parece que Judith Butler, em seu texto para o catálogo, também poderia ser alocada nessa linhagem. A filósofa inicia o texto perguntando quem e o quê se levanta quando há um levante, buscando sua principal motivação em um limite que foi alcançado, uma situação de sofrimento que atinge a marca do intolerável (BUTLER, J. 2017, p. 23). O levante democrático, para ela, teria sempre uma finalidade ou um objetivo que estão voltados para a liberdade, a justiça, a autodeterminação e a igualdade.

Ele seria uma forma real e coletiva da convicção de que a sujeição foi longe demais, provocando situações de intolerável injustiça. Embora caracterizado como um acontecimento pontual, que sempre encontraria um fim e um fracasso, o levante se inscreveria na história e conquistaria uma narrativa que ilumina novos ideais (idem, p. 30). Por isso, em boa parte dos casos seria possível traçar uma relação entre os vários episódios, compondo um processo em curso, uma "história cumulativa" na qual "um levante sempre cita o outro e é animado pelas imagens e narrativas do anterior" (idem, p. 31).

O problema das duas maneiras de caracterizar os levantes é, justamente, tratá-los como uma sequência de imagens que torna visível uma aspiração por outro futuro. Assim, cada levante funciona naquele mesmo registro do museu de Hiroshima: torna o fato visível, mas com o preço de inscrevê-lo em uma memória coletiva que aponta para grupos, classes, movimentos e um lugar comum. A história funciona como a fiel depositária dos sedimentos e imagens que permanecem a espera da irrupção do próximo acontecimento. A passagem da negatividade da indignação para a positividade do levante constituinte só é apreendida quando passa pelo crivo de imagens já disponíveis no grande corredor da história revolucionária ("da Comuna à Primavera Árabe”). Não são os levantes que lançam uma nova miríade de pontos de vista que arrastam o nosso olhar para o espaço árido das potências 
informes e de seus mundos possíveis, ainda que inacabados ou precariamente esboçados. Eles permanecem em uma espécie de mundo exterior, esperando que os juízos dos filósofos da política decidam sobre sua natureza, seu estatuto e o seu local no cintilante museu dos acontecimentos insurgentes.

Em sentido contrário, a segunda tendência geral pode ser compreendia como a passagem do juízo a uma estética dos levantes. Para David Lapoujade, se a política começa pela estética não é porque ela deva ser estetizada ou vice-versa, mas porque "tudo começa com ver e falar - e porque é pela estética que podemos remontar as condições mesmas da experimentação" (LAPOUJADE, D. 2015, p. 280). É a mesma premissa adotada por Rancière em sua conhecida distinção entre polícia e política: enquanto a primeira ordena o nosso campo de percepção produzindo consenso, a segunda: "faz ver o que não cabia ser visto, faz ouvir um discurso ali onde só tinha lugar o barulho" (RANCIERE, J. 1995/1996, p. 42).

Mas como ver? Como tornar mais real aquilo que já existe, mas não possui força suficiente para fender a ordem das palavras e das coisas? Que gestos são necessários para que determinados modos de existência ganhem mais consistência, extensão e intensidade? É novamente David Lapoujade que propõe a discussão, a partir da recuperação de uma "arte da ontologia" no trabalho do filósofo Étienne Souriau. Através da qual, uma estética do Ser é pensada pela infinita variedade de seus modos e maneiras de existência. (LAPOUJADE, D. 2017, p. 13). A primeira afirmação desse pluralismo existencial é que "não há um único modo de existência para todos os seres que povoam o mundo, como também não existe um único mundo para todos os seres (...)" (idem, p. 14). Trata-se de perceber as diversas artes de existir que participam, não sem realizar inúmeras travessias, dos vários planos ou dos vários mundos compostos e decompostos pelas diferentes perspectivas lançadas.

Além disso, o critério de distinção entre os modos de existência não é próprio de cada modo, mas se refere às condições pelas quais cada realidade se coloca (idem, p. 34). Assim, dentre os vários modos de existência, os fenômenos levantam estruturas fugidias e instantâneas (ex: uma nuvem rósea no céu) e graças ao seu poder de nuance recompõe toda a paisagem. As coisas, por sua vez, levantam uma permanência e um ímpeto de conservação, formando com outras coisas uma unidade estável e sistemática (ex: o próprio corpo humano). Os imaginários existem enquanto sustentado por crenças e afetos (ex: o monstro no quarto escuro da criança). Os virtuais são esboços, fragmentos, potencialidades que apontam para 


\section{RFD}

um leque de novas possibilidades de existência e, portanto, não podem ser confundidos com a simples inexistência (ex: uma pequena história sugestiva ouvida por um escritor).

Contudo, dentro dos universos compostos pelos diversos modos de existência, para Souriau, os virtuais possuem um estatuto especial. Eles formam o universo mais rico e mais amplo, uma nuvem que está sempre à nossa volta, mas que é também o mais evanescente e mais próximo do nada (idem, p. 38). Eles não definem uma arte por si mesmos, mas exigem que uma arte seja criada, que gestos possam lhe dar uma existência mais real. No mesmo plano, é através dessa nuvem de potencialidades que novas realidades podem ser criadas, ou seja, os virtuais dependem de um gesto de criação, assim como toda a criação depende de uma percepção e de uma exploração dessa nuvem de potencialidades. Saímos, portanto, do domínio das existências estáticas e passamos para o campo de criação e transformação dos próprios modos de existência: da modalidade para a transmodalidade.

\section{CONCLUSÃO}

Voltamos à questão: como perceber e como dar mais consistência aos virtuais? Lapoujade recupera o exemplo da mãe que desarruma os objetos cuidadosamente compostos por uma criança em cima da mesa, fazendo-a chorar. O que faltou a mãe? O que ela não viu? Decerto, criança e mãe enxergam a mesa e todos os objetos sobre elas dispostos. Mas faltou a mãe perceber o modo de existência próprio desses objetos, com suas arquiteturas e virtualidades, do ponto de vista da criança. É por trabalhar com outro conjunto de dados - a exigência de limpar a mesa, organizar a casa, garantir a ordem do mundo - que ela não vê e não é capaz de explorar outras possibilidades (idem, p. 44). Existem, assim, inúmeras aberturas e fendas desenhadas pelos virtuais na ordem das coisas, mas raros são aqueles que se deixam arrastar por essas brechas, tanto para percebê-las, como para traçar a partir delas um espaço de criação.

Portanto, para uma estética da política o mais importante não seria ter um ponto de vista prévio que se lança sobre os levantes, enquadrando-os em imagens e enunciados já formados na mesa dos filósofos da política ou nas reuniões de conjuntura dos ativistas e militantes políticos. Trata-se de mudar a própria arquitetura que sustenta uma perspectiva ordenadora do mundo e reconhecer que os levantes, eles mesmos, nos interpelam com seus 
pontos de vista e perspectivas, dando consistência e realidade a outros mundos e modos de existência a serem explorados ou seguidos.

$\mathrm{Na}$ introdução que abre o catálogo da exposição Levantes, Didi-Huberman não caracteriza os tempos sombrios como o momento que a humanidade precisa enfrentar a força e a aparição súbita de um grande Mal que aterroriza as boas almas do mundo. Para ele, "os tempos sombrios só são tão sombrios por baterem na nossa cara, comprimirem nossas pálpebras, ofuscarem o nosso olhar. Como fronteiras que se impõem em nosso próprio corpo e pensamento". Eles são "cinza como os dias chuvosos" e como as capas de chumbo que pensam sobre nossas existências (HUBERMAN, D. 2017a, p. 15).

Talvez seja o caso, então, de opor ao cinza e à gravidade dos dias chuvosos a luminosidade e a força árida do deserto. É que os levantes nos permitiriam o reencontro com o fascínio, com aquilo que desvia e arrasta o olhar para um espaço mais leve, onde luzes podem ser esculpidas e outros enunciados podem ser encontrados. Ele possibilita, além disso, que os juízos sejam interrompidos para que um novo campo de experimentação apareça: uma estética dos gestos, dos modos e das maneiras de ser. É aqui que ética, estética e política se encontram: trata-se de seguir os traços e rastros deixados pelos levantes, mesmo que eles nos levem para uma lógica do desvio, da ambiguidade, da errância e de circularidades sempre aberrantes. Retornamos, assim, ao problema kafkiano por excelência: como reencontrar os mundos durante o caminho sem objetivo que é o deserto?

\section{BIBLIOGRAFIA}

BLANCHOT, M. The infinite conversation. Minneapolis: Minnesota University Press, 1993. . O espaço literário. Rio de Janeiro: Rocco, 2011.

BUTLER, J. Levante. In: DIDI-HUBERMAN, G. [Org.] Levantes. São Paulo: SESC, 2017.

DELEUZE, G. A imagem-tempo. Cinema 2. São Paulo: Brasiliense, 2013.

DELEUZE, G; GUATTARI, F. Kafka: para uma literatura menor. Lisboa: Assírio \& Alvin, 2002.

. "Mai 68 n'a pas eu lieu". In: LAPOUJADE, D. (Org.). Deux régimes de fous et autres textes. Paris: Les Éditions de Minuit, 2003.

DIDI-HUBERMAN, G. Introdução. In: DIDI-HUBERMAN, G [Org.] Levantes. São Paulo: SESC, 2017. 
. Quando as imagens tomam posição: o olho da História, I. Belo Horizonte: Editora UFMG, 2017b.

HIROSHIMA Mon Amour. Direção: Alain Resnais. Roteiro: Marguerite Duras. França/Japão. Argo filmes, 1959.

LAPOUJADE, D. Deleuze, os movimentos aberrantes. São Paulo: n-1 edições, 2015. . Existências mínimas. São Paulo: n-1 edições, 2015.

NEGRI, A. O acontecimento "levante" In: DIDI-HUBERMAN, G. Levantes. São Paulo: SESC, 2017.

RANCIÈRE, J. O desentendimento. São Paulo: Editora 34, 1996. 